\title{
Erratum to: A robust asymmetry in loudness between rising- and falling-intensity tones
}

\author{
Emmanuel Ponsot • Patrick Susini • Sabine Meunier
}

Published online: 7 March 2015

(C) The Psychonomic Society, Inc. 2015

Erratum to: Atten Percept Psychophys

DOI 10.3758/s13414-014-0824-y

One sentence in the article's Results section is not an accurate account of the work it refers to (Hellström, 1979, 2003). This sentence appears under the subheading Time order errors in the middle of the text. The amended formulation appears below.

"One of the suggestions proposed to explain TOEs is that the two stimuli are weighted differently, a greater weight often being accorded to the second stimulus (Hellström 1979, 2003). As a consequence, when the levels of the two tones are in low intensity regions, the first stimulus is overestimated relative to the second (a positive TOE), and when they are in high regions, the first stimulus is underestimated relative to the second (a negative TOE)."

The online version of the original article can be found at http://dx.doi.org/ 10.3758/s13414-014-0824-y.

E. Ponsot $(\bowtie) \cdot$ P. Susini

STMS Laboratory (IRCAM, CNRS, UPMC), 1 place Igor

Stravinsky, 75004 Paris, France

e-mail: ponsot@ircam.fr

P. Susini

e-mail: patrick.susini@ircam.fr

\section{S. Meunier}

LMA, CNRS, UPR 7051, Aix-Marseille University, Centrale

Marseille, 13402 Marseille Cedex 20, France

e-mail: meunier@lma.cnrs-mrs.fr 